\title{
Primary Prevention and Delay of Onset of AD/Dementia
}

\author{
Howard H. Feldman, Claudia Jacova
}

\begin{abstract}
Prevention in Alzheimer's disease and other dementias (AD/dementia) is defined on the basis of clinical states and their expressed symptoms. Primary prevention refers to delaying the development of the full-blown state of clinically expressed disease in normal individuals. Current primary prevention research is driven by evidence of $\mathrm{AD} /$ dementia protective factors that have emerged from epidemiological studies. The first randomized controlled trials (RCTs) of primary AD/dementia prevention have been designed to test the efficacy and safety of NSAIDs, hormonal therapy, antihypertensive drugs and antioxidants. The experience of these trials has indicated safety concerns as a key issue and highlighted significant design challenges in this type of research. These trials have required large sample sizes and unsustainable costs. There should be consideration given in future trials to enriching study samples with risk factors to increase progression rates to AD/dementia. Innovative strategies will also be needed to recruit and retain subjects given the long follow-up periods, modest perceived benefit and the potential for the risk-benefit ratio to change during the trial. It is foreseeable that regulatory authorities will be presented with primary prevention RCTs for approval and labelling, and that criteria to evaluate such evidence still need to be developed.
\end{abstract}

RÉSUMÉ: Prévenir et retarder l'apparition de la MA/démence. La prévention de la maladie d'Alzheimer (MA) et des autres démences (MA/démence) se définit sur des bases cliniques et symptomatiques. En prévention primaire, on cherche à retarder l'apparition de la maladie avérée au point de vue clinique chez des individus normaux. Actuellement, la recherche en prévention primaire est basée sur des données provenant d'études épidémiologiques sur les facteurs de protection contre la MA/démence. Les premiers essais contrôlés randomisés (ECRs) en prévention primaire sur la MA/démence ont été conçus pour évaluer l'efficacité et la sécurité d'AINSs, de traitements hormonaux, d'antihypertenseurs et d'antioxydants. L'expérience acquise au cours de ces études a soulevé des questions importantes concernant la sécurité et a fait ressortir des défis importants quant au plan de ce type de recherche. Ces essais nécessitent de très grands échantillons et entraînent des coûts prohibitifs. À l'avenir, on devrait considérer enrichir les groupes en incluant des sujets ayant des facteurs de risque afin d'augmenter le taux de progression à la MA/démence. Des stratégies novatrices seront également nécessaires pour recruter et maintenir la participation des sujets aux études étant donné le suivi à long terme, les bénéfices perçus comme étant modestes et le taux de risques/bénéfices qui peut changer pendant l'étude. Il est à prévoir que des ECRs en prévention primaire seront présentés aux organismes de régulation pour approbation et étiquetage du conditionnement des médicaments et que des critères d'évaluation des données ainsi générées devront être développés.

Can. J. Neurol. Sci. 2007; 34: Suppl. 1 - S84-89

There are approximately 350,000 Canadians estimated to be suffering from dementia today, the majority (65\%) from Alzheimer's disease (AD). The incidence rate of dementia in Canada is estimated at 20.6 new cases per 1,000 per annum. With the projected growth of the senior population, the number of affected individuals is predicted to increase to over a million in the next three decades. ${ }^{1}$ The associated costs of dementia are incalculable for the patients and their families, and are anticipated to be staggering for Canada's health system. In 1991 a conservative health-economic study from the Canadian Study of Health and Aging (CSHA) estimated the cost of care at \$3.9 billion per year, with anticipated escalating forward costs. ${ }^{2}$ Taken together, these data provide a pressing target for aging and dementia research directed at enabling individuals to maintain

From the Division of Neurology, Department of Medicine, University of British Columbia, Vancouver, B.C., Canada.

Received OCtober 31, 2005. ACCEPTED IN FINAL FORM APriL 2, 2006. Reprint requests to: Howard H. Feldman, Division of Neurology, UBC Hospital, S 192-2211 Wesbrook Mall, Vancouver, B.C., V6T 2B5, Canada. 
their cognitive capacity into old age, delaying the onset of impairment, and reducing the number of people affected by dementia. In this context, research strategies are now aiming at the prevention of $\mathrm{AD}$ and other dementias (AD/dementia). This paper proposes a framework for studies on the prevention of $\mathrm{AD} /$ dementia, examines candidate interventions for prevention and addresses the challenges that research will face in testing their efficacy.

\section{What is Meant by Prevention of AD/Dementia}

Primary prevention in $\mathrm{AD} /$ dementia refers to delaying the development of the full-blown state of clinically expressed disease in normal individuals, while secondary prevention refers to delaying the progression from earliest symptom expression to an overt disease state. Tertiary prevention coincides with treatment, aiming to slow, stop or reverse the progression of overt clinical disease. Because the pathogenesis of $\mathrm{AD} /$ dementia is believed to begin years before symptom expression and its onset is impossible to date, the lines between the state of normal, early and overt disease are imprecise. At present the clinical states of $\mathrm{AD} /$ dementia and its expressed symptoms are the only available endpoints for prevention studies.

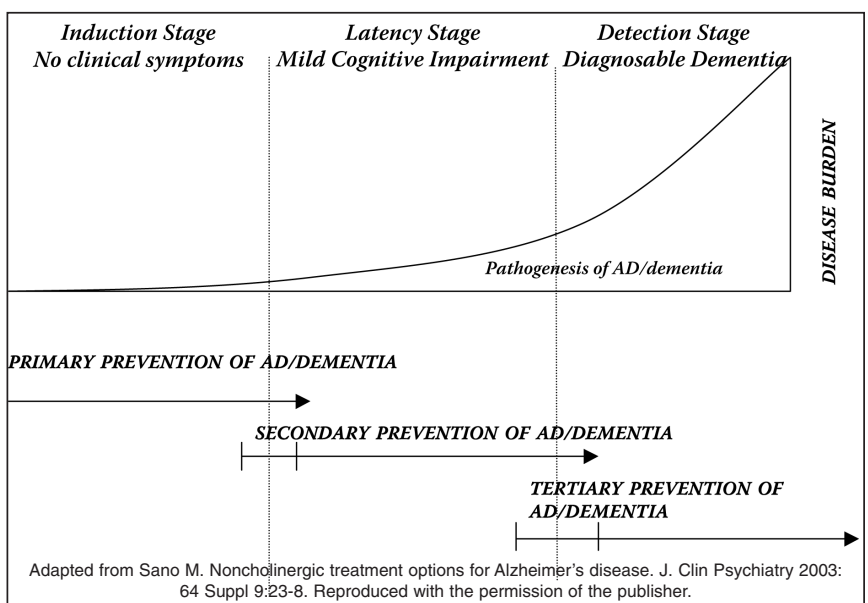

Figure: Pathogenesis, clinical states and prevention approaches to AD/dementia.

The Figure presents the conceptual model of the relationship between the clinical stages of disease development and the three preventive approaches, set against the continuum of the pathological process underlying dementia. ${ }^{3}$ At the induction stage there are no clinical symptoms present despite the early subtle brain changes that are believed to occur in individuals who are eventually destined to develop the disease. At the latency stage, there are clinical symptoms, currently known as Mild Cognitive Impairment $(\mathrm{MCI})^{4}$ or Cognitive Impairment Not Dementia (CIND). ${ }^{5}$ These symptoms can be accompanied by more defined pathological processes measurable on MRI, ${ }^{6,7}$ PET, 8,9 and post-mortem neuropathology. ${ }^{10}$ The percentage of MCI cases that advance to $\mathrm{AD} /$ dementia is 10 to $15 \%$ per annum, ${ }^{11}$ compared to 1 to $2 \%$ for normal subjects. ${ }^{1}$ Mild Cognitive Impairment is therefore an ideal stage for secondary preventive interventions. Where MCI does advance to $\mathrm{AD} /$ dementia, the detection stage of diagnosable $\mathrm{AD} /$ dementia is reached, with its pathological cascade of apoptosis, inflammatory changes, increasing amyloidopathy and tangle formation.

There is an important current assumption underlying primary prevention of $\mathrm{AD} /$ dementia. For successful prevention to occur, the onset of the disease would have to be delayed in a sizeable group of at-risk individuals some of whom will die of other causes prior to the diagnosable $\mathrm{AD} /$ dementia state. It has been calculated that interventions capable of producing even a modest delay in onset, such as 1 year, would reduce $\mathrm{AD} /$ dementia prevalence by $7 \%$ in 10 years and by $9 \%$ in 30 years. Delaying the onset by 5 years could potentially reduce the prevalence by $40 \%$ in 10 years and by as much as $50 \%$ in 30 years. $^{12}$

\section{How to Identify Candidate InTERVENTIONS}

Research on prevention of AD/dementia has been —and will likely continue to be- driven by evidence of protective factors emerging from retrospective case-control and prospective cohort studies of dementia. A large number of medication, health and lifestyle factors including the use of statins, ${ }^{13-15}$ non-steroidal anti-inflammatory (NSAID) drugs, ${ }^{16,17}$ vitamins,${ }^{18}$ estrogens, ${ }^{19,20}$ participation in cognitively demanding activities, ${ }^{21-23}$ and physical exercise, ${ }^{24}$ have been associated with a reduced risk of dementia. These associations suggest that a spectrum of interventions - pharmacological treatments, nutritional supplements and lifestyle modifications - might have preventive effects. However, these association studies must be tested through randomized controlled trials (RCTs) before any intervention can be scientifically accepted and considered for widespread application within the healthy population. The Women's Health Initiative Memory Study (WHIMS) found that treatment with conjugated equine estrogen, alone or in combination with medroxyprogesterone, was associated with an increased risk of developing cognitive impairment and dementia. ${ }^{25,26}$ The WHIMS outcome serves as a vivid reminder that factors identified as protective of $\mathrm{AD} /$ dementia in association studies do not necessarily have a preventive effect when tested more definitively in an RCT.

Beyond the epidemiological leads, the risk-benefit ratio of candidate interventions must be carefully considered. Primary prevention interventions should be sufficiently safe to be given to healthy normal individuals without causing harm. They should be affordable such that widespread use can follow. In addition, compliance needs to be high and maintained over long periods of time. Lastly, any such intervention should ideally have a biologically plausible mechanism of action within the framework of $\mathrm{AD} /$ dementia pathogenesis.

\section{Current Status of Primary Prevention Trials}

To identify primary prevention RCTs of AD/dementia, PubMed and the US National Institutes of Health clinical trials 
web site (www.ClinicalTrials.gov) were searched. The search yielded eight primary prevention RCTs summarized in the Table. These trials address the efficacy and safety of NSAIDs (Naproxen and Celecoxib), hormonal therapy (estrogen and progesterone), antihypertensive drugs (Nitrendipine, Enalapril and Hydrochlorothiazide; Candesartan), antioxidants (Ginkgo Biloba) and supplements (Vitamin E and Selenium). The antihypertensive drug trials (Syst-Eur and SCOPE) have been completed, with mixed results. In Syst-Eur a reduction in dementia incidence was observed in the treated group, ${ }^{27}$ whereas in SCOPE there was no difference in incident cases between the treated and control group. ${ }^{28}$ Three RCTs (ADAPT, WHIMS and PREPARE) have been halted because of emerging safety concerns. ADAPT was discontinued for reasons of unacceptable toxicity, where a risk of cardiovascular events in association with naproxen arose. ${ }^{29}$ The WHIMS and PREPARE trials of conjugated equine estrogen alone, or in combination with medroxyprogesterone acetate, have been halted because of increased risks of breast cancer and cardiovascular problems. ${ }^{25}$ GEMS,${ }^{30}$ GuidAge, ${ }^{31}$ and PREADVISE ${ }^{32}$ are in process, with results not anticipated for some considerable length of time.

This first generation of trials does not address the full range of potentially efficacious preventive strategies. Of potential interest for future primary prevention trials will be agents with anti-amyloidogenic action, hyperlipidaemia-lowering drugs including statins, ${ }^{33,34}$ and agents capable of reducing hyperhomocysteinemia, neuronal DNA damage and apoptosis. ${ }^{35}$

\section{Design and Methodological Challenges for Primary Prevention RCTs}

Prevention RCTs face unique challenges, some of which have already emerged from the first generation of trials.

(1) Sample sizes and costs: As seen in the Table, primary prevention RCTs have required very large sample sizes $(n=900$

Table: Placebo-controlled AD/dementia prevention RCTs (ongoing and completed)

\begin{tabular}{|c|c|c|c|c|c|c|}
\hline $\begin{array}{l}\text { Trial } \\
\text { (Acronym) }\end{array}$ & Status & Intervention & $\begin{array}{l}\text { Subject selection } \\
\text { criteria }\end{array}$ & $\begin{array}{c}\text { Duration } \\
\text { (years) }\end{array}$ & $\begin{array}{l}\text { Overall } \\
\text { estimated } \\
\text { incidence } \\
\text { rate }(\% \\
\text { per year }\end{array}$ & $\begin{array}{l}\text { Planned } \\
\text { sample } \\
\text { size }\end{array}$ \\
\hline PREPARE & Discontinued & $\begin{array}{l}\text { Conjugated equine } \\
\text { estrogen alone } \\
\text { Conj. equ. estrogen }+ \\
\text { medroxyprogesterone } \\
\text { acetate }\end{array}$ & $\begin{array}{l}\text { Female sex } \\
\text { Family history of } A D \\
\text { Age } \geq 65\end{array}$ & 3 & 5 & 900 \\
\hline$A D A P T$ & Discontinued & $\begin{array}{l}\text { Naproxen or } \\
\text { Celecoxib }\end{array}$ & $\begin{array}{l}\text { Family history of dementia } \\
\text { Age } \geq 70\end{array}$ & $5-7$ & $3-3.4$ & 2,800 \\
\hline SYST-EUR & Completed & $\begin{array}{l}\text { Nitrendipine and/or } \\
\text { Enalapril and/or } \\
\text { Hydrochlorothiazide }\end{array}$ & $\begin{array}{l}\text { Systolic hypertension } \\
\text { Age } \geq 60\end{array}$ & 5 & 1.6 & 3,000 \\
\hline SCOPE & Completed & Candesartan cilexetil & $\begin{array}{l}\text { Systolic hypertension } \\
\text { Age } 70 \text { to } 89\end{array}$ & $3-5$ & 2.4 & 4,000 \\
\hline GEMS & $\begin{array}{l}\text { Ongoing } \\
\text { extended }\end{array}$ & Ginkgo biloba & $\begin{array}{l}\text { Age } \geq 75 \text { ( } \geq 71 \text { if of African } \\
\text { ancestry) }\end{array}$ & 5 & 4 & 3,000 \\
\hline GUIDAGE & Ongoing & Ginkgo biloba & $\begin{array}{l}\text { Age } \geq 70 \\
\text { Memory complaints }\end{array}$ & 5 & $\begin{array}{l}\text { Not } \\
\text { available }\end{array}$ & 2,800 \\
\hline WHIMS & Discontinued & $\begin{array}{l}\text { Conjugated equine } \\
\text { estrogen alone } \\
\text { Conj. equ. estrogen }+ \\
\text { medroxyprogesterone } \\
\text { acetate }\end{array}$ & $\begin{array}{l}\text { Female sex } \\
\text { Age } \geq 65\end{array}$ & 6 & 2 & 8,300 \\
\hline PREADVISE & Ongoing & $\begin{array}{l}\text { Vitamin E or } \\
\text { Selenium or Both }\end{array}$ & $\begin{array}{l}\text { Age } \geq 62 \text { ( } \geq 60 \text { if of African } \\
\text { or Hispanic ancestry) }\end{array}$ & $9-12$ & 1 & 10,700 \\
\hline
\end{tabular}


to 10,700 , average roughly 4,500 ) and long follow-up times ( 3 to 12 years, average roughly 6 years). These numbers have been necessary because of the low projected incident rate of dementia (range 1 to $5 \%$ per year) in the study populations. In turn the costs have been formidable, not likely sustainable in the Canadian funding environment. The two largest trials (WHIMS and PREADVISE) have targeted entirely non-selected study populations whereas the other trials have enriched their study samples with a limited number of $\mathrm{AD} /$ dementia risk factors to increase the incidence rate and reduce the number of required participants. These enriching risk factors have included a family history of $\mathrm{AD} /$ dementia in a first-degree relative, ${ }^{29}$ old age, ${ }^{30}$ systolic hypertension ${ }^{27,28}$ and memory complaints. ${ }^{31}$ Efforts will be warranted in future trial designs to increase the rate of dementia progression by further enrichment techniques, that might include a larger number of risk factors related to demographics, genomic profiles, vascular history and neuroimaging. The settings of the research study and the source of recruited subjects likely impact progression to $\mathrm{AD} /$ dementia rates and should also be carefully considered as a potential enrichment technique.

Enrichment of study samples with $\mathrm{AD} /$ dementia risk factors can be viewed as a potential strategy to optimally investigate putative preventive agents. Smaller samples could establish proof-of-principle as a prelude to larger-scale studies. This would also allow a range of existing/emerging epidemiological leads to be pursued within a reasonable time frame. Within enriched studies the magnitude of treatment effect sizes could be assessed.

(2) Projected rates of progression to AD/dementia: The projected progression rates appear likely to have been overestimated in the initial primary prevention RCTs. This raises important considerations for future studies with some speculation. The participation in a prevention trial may carry with it a beneficial impact on subjects' health that extends beyond the intervention that is being tested. Subjects may become more motivated to engage in health promoting behaviours including diet, exercise patterns and other riskmodification. They benefit from receiving careful medical follow-up within the trial over long periods of time, with appropriate identification and treatment of new health problems. In interventions that are non-prescriptional, the non-protocol use of the target treatments cannot be precluded as these are usually readily available and subjects may wish to 'hedge their bets'. By their nature, prevention trials may attract highly health-conscious subjects who are not representative of the populations from which the initial AD/dementia incidence rates have been derived. Taken together, these factors may culminate in unattainable projected rates of $\mathrm{AD} /$ dementia progression, resulting in the need for additional time and further resources to complete trials (see Table).

(3) Recruitment and retention: Innovative strategies will be needed to recruit and retain subjects in prevention trials. The recruitment of elderly participants into long-term studies is known to be problematic, ${ }^{36}$ yet this is the group with the highest risk of progression to $\mathrm{AD} /$ dementia. As previously pointed out, there may be a potential problem of over-representation of very successfully aging subjects. This has already been reported in the Syst-Eur trial where subjects' median MMSE score at study entry was $29 .{ }^{27}$ Recruitment problems may be further exacerbated by the requirement of an informant for participation in the trial.

Retention of subjects will also pose problems, given long follow-up periods, modest perceived benefit and the potential for the risk-benefit ratio to change during these periods (e.g. NSAIDs in ADAPT, and estrogens in PREPARE and WHIMS). The first generation of trials underscores that non-adherence and loss to follow-up will be significantly higher than predicted. Provisions will have to be made for sample sizes that preserve adequate power through trials. To enhance compliance, followup strategies that do not involve on-site visits (e.g., telephone interviews) may be useful, as might the conduct of the study within usual care settings, i.e. General Practitioner offices.

(4) Study endpoints: The clinically defined endpoints of $\mathrm{AD} /$ dementia prevention RCTs have intrinsic limitations. The validity of clinical states (normal, MCI, dementia) and state transitions is limited by the absence of conclusively established biological markers within a continuous disease process. Yet, time to diagnosis of $\mathrm{AD} /$ dementia is the primary outcome measure in RCTs and its accurate determination is critical. In multi-centre RCTs, rater and centre biases in the measurement of time to diagnosis can be anticipated. On the horizon, biomarkers in development ${ }^{37-39}$ may assist, or even become surrogate outcomes; however at present they cannot provide evidence of efficacy independent of clinical criteria.

(5) Timing of interventions: Prevention RCTs will have to systematically investigate the relation between time of intervention and treatment effect. The WHIMS trial found that treatment with estrogen plus progestin was unsuccessful in reducing the incidence of $\mathrm{AD} /$ dementia in women aged 65 years or older, ${ }^{25}$ though it has been suggested that if such treatment were initiated around menopause (10 years earlier), there might have been a positive treatment effect. ${ }^{40}$ There have been suggestions that also other pharmacological interventions may exert their most significant effects in midlife, long before the age of concern for $\mathrm{AD} /$ dementia. ${ }^{41}$

\section{Conclusions}

Research on the therapeutics of AD/dementia has traditionally focused on treating diagnosed disease. However researchers in the field have increasingly advocated that attention be turned to the possibility of preventing dementia. ${ }^{42-44}$ Currently the primary prevention of $\mathrm{AD} /$ dementia should be understood as delaying the onset of diagnosable disease. In turn this delay will effectively eliminate a number of $\mathrm{AD} /$ dementia cases as individuals die of other causes before they cross the threshold of diagnosable disease. Evidence of protective factors already exists and offers good leads as to candidate interventions that might be effective. The first prevention RCTs have been designed to test NSAIDs, hormonal therapy, antihypertensive drugs, antioxidants and supplements. The experience of these RCTs has indicated safety concerns as a key issue in research on preventive interventions. Significant design and methodological challenges have been highlighted that will need to be addressed in future trials.

It is foreseeable that regulatory authorities will be presented with primary prevention RCTs for approval and labelling. The regulatory criteria to evaluate such evidence will need to be developed. These decisions about approval and labelling of 
preventive interventions will have to define the acceptable risks and the standards for minimum treatment effect sizes.

\section{DEClaRATION}

Howard Feldman receives support through the CIHR operating grant IAP-73376 "Preventing AD and other dementias: The development of a statistical framework for randomised controlled trials". Claudia Jacova is funded by a post-doctoral Canadian Institutes of Health Research/Michael Smith Foundation for Health Research Training Fellowship in Neurobiology and Behaviour.

\section{REFERENCES}

1. Canadian Study of Health and Aging Working Group. Canadian Study of Health and Aging: Study methods and prevalence of dementia. CMAJ. 1994; 150: 899-913.

2. Ostbye T, Crosse E. Net economic costs of dementia in Canada. CMAJ. 1994; 151(10): 1457-64.

3. Sano M. Noncholinergic treatment options for Alzheimer's disease. J Clin Psychiatry. 2003; 64 Suppl 9: S23-8.

4. Petersen RC. Aging, mild cognitive impairment, and Alzheimer's disease. Neurol Clin. 2000; 18: 789-806.

5. Graham JE, Rockwood K, Beattie BL, Eastwood R, Gauthier S, Tuokko H, et al. Prevalence and severity of cognitive impairment with and without dementia in an elderly population. Lancet. 1997; 349: 1793-6.

6. Jack CR, Petersen RC, Xu Y, O'Brien PC, Smith GE, Ivnik RJ, et al. Rates of hippocampal atrophy correlate with change in clinical status in aging and AD. Neurology. 2000; 55: 484-9.

7. Kaye JA, Swihart T, Howieson D, Dame A, Moore MM, Karnos T, et al. Volume loss of the hippocampus and temporal lobe in healthy elderly persons destined to develop dementia. Neurology. 1997; 48: 1297-304.

8. De Santi S, de Leon MJ, Rusinek H, Convit A, Tarshish CY, Roche A, et al. Hippocampal formation glucose metabolism and volume losses in MCI and AD. Neurobiol Aging. 2001; 22: 529-39.

9. Drzezga A, Lautenschlager N, Siebner H, Riemenschneider M, Willoch F, Minoshima S, et al. Cerebral metabolic changes accompanying conversion of mild cognitive impairment into Alzheimer's disease: a PET follow-up study. Eur J Nucl Med Mol Imaging. 2003; 30: 1104-13

10. Markesbery WR. Neuropathological criteria for the diagnosis of Alzheimer's disease. Neurobiol Aging. 1998; 18 (suppl 4): S13-9.

11. Petersen RC, Doody R, Kurz A, Mohs RC, Morris JC, Rabins PV, et al. Current concepts in mild cognitive impairment. Arch Neurol. 2001; 58(12): 1985-92.

12. Brookmeyer R, Gray S, Kawas C. Projections of Alzheimer's disease in the United States and the public health impact of delaying disease onset. Am J Public Health. 1998; 88: 1337-42.

13. Rockwood K, Kirkland S, Hogan DB, MacKnight C, Merry H, Verreault $\mathrm{R}$, et al. Use of lipid-lowering agents, indication bias, and the risk of dementia in community-dwelling elderly people. Arch Neurol. 2002; 59(2): 223-7.

14. Jick H, Zornberg GL, Jick SS, Seshadri S, Drachman DA. Statins and the risk of dementia. Lancet. 2000; 356: 1627-31.

15. Wolozin B, Siegel G. Decreased prevalence of Alzheimer disease associated with 3-Hydroxy-3-Methyglutaryl Coenzyme A reductase inhibitors. Arch Neurol. 2000; 57: 1439-43.

16. McGeer PL, Schulzer M, McGeer EG. Arthritis and antiinflammatory agents as possible protective factors for Alzheimer's disease: a review of 17 epidemiologic studies. Neurology. 1996; 47: 425-32.

17. in t'Veld VB, Ruitenberg A, Hofman A, Launer LJ, van Duijn CM, Stijnen T, et al. Nonsteroidal antiinflammatory drugs and the risk of Alzheimer's disease. N Engl J Med. 2001; 345(21): 1515-21.

18. Zandi PP, Anthony JC, Khachaturian AS, Stone SV, Gustafson D, Tschanz JT, et al. Reduced risk of Alzheimer disease in users of antioxidant vitamin supplements: the Cache County Study. Arch Neurol. 2004; 61(1): 82-8.
19. Henderson VW, Paganini-Hill A, Emanuel CK, Dunn ME, Buckwalter JG. Estrogen replacement therapy in older women. Arch Neurol. 1994; 51: 896-900.

20. Kawas C, Resnick S, Morrison A, Brookmeyer R, Corrada MZ, Bacal $\mathrm{C}$, et al. A prospective study of estrogen replacement therapy and the risk of developing Alzheimer's disease: the Baltimore Longitudinal Study of Aging. Neurology. 1997; 48: 1517-21.

21. Bosma H, van Boxtel MP, Ponds RW, Houx PJ, Burdorf A, Jolles J. Mental work demands protect against cognitive impairment: MAAS prospective cohort study. Exp Aging Res. 2003; 29: 33-45.

22. Verghese J, Lipton RB, Katz MJ, Hall CB, Derby CA, Kuslansky G, et al. Leisure activities and the risk of dementia in the elderly. $\mathrm{N}$ Engl J Med. 2003; 348(25): 2508-16.

23. Wilson RS, Mendes De Leon CF, Barnes LL, Schneider JA, Bienias JL, Evans DA, et al. Participation in cognitively stimulating activities and risk of incident Alzheimer disease. JAMA. 2002; 287: 742-8

24. Lindsay J, Laurin D, Verreault R, Hebert R, Helliwell B, Hill GB, et al. Risk factors for Alzheimer's disease: a prospective analysis from the Canadian Study of Health and Aging. Am J Epidemiol. 2002; 156 (5): 445-53.

25. Shumaker SA, Legault C, Thal L, Wallace RB, Ockene JK, Hendrix SL, et al. Estrogen plus progestin and the incidence of dementia and mild cognitive impairment in postmenopausal women: the women's health initiative memory study: randomized controlled trial. JAMA. 2003; 289(20): 2651-62.

26. Shumaker SA, Legault C, Kuller L, Rapp SR, Thal L, Lane DS, et al. Conjugated equine estrogens and incidence of probable dementia and mild cognitive impairment in postmenopausal women: Women's Health Initiative Memory Study. JAMA. 2004; 291(24): 2947-58.

27. Forette F, Seux ML, Staessen JA, Thijs L, Birkenhager WH, Babarskiene MR, et al. Prevention of dementia in randomised double-blind placebo-controlled Systolic Hypertension in Europe (Syst-Eur) trial. Lancet. 1998; 352: 1347-51.

28. Lithell H, Hansson L, Skoog I, Elmfeldt D, Hofman A, Olofsson B, et al. The study on cognition and prognosis in the elderly (SCOPE): principal results of a randomized double-blind intervention trial. J Hypertens. 2003; 21: 875-86.

29. Boyles S. Naproxen may increase risk of heart disease. 2005. Available from: http://www.medscape.com/viewarticle/496403.

30. CHS Coordinating Center. Ginkgo Evaluation of Memory Study. 2003. Available from: http://www.nccam-ginkgo.org.

31. Vellas B, Andrieu S, Ousset PJ, Ouzid M, Mathiex-Fortunet H. The GuidAge study: Methodological issues. A 5-year double-blind randomized trial of the efficacy of EGb 761(R) for prevention of Alzheimer disease in patients over 70 with a memory complaint. Neurology. 2006 Nov 14;67(9 Suppl 3):S6-11.

32. Kryscio RJ, Mendiondo MS, Schmitt FA, Markesbery WR. Designing a large prevention trial: statistical issues. Stat Med. 2004; 23: 285-96.

33. Sjogren M, Gustafsson K, Syversen S, Olsson A, Edman A, Davidsson P, et al. Treatment with simvastatin in patients with Alzheimer's disease lowers both alpha- and beta-cleaved amyloid precursor protein. Dement Geriatr Cogn Disord. 2003; 16: 25-30.

34. Fassbender K, Simons M, Bergmann C, Stroick M, Lutjohann D, Keller P, et al. Simvastatin strongly reduces levels of Alzheimer's disease beta -amyloid peptides Abeta 42 and Abeta 40 in vitro and in vivo. Proc Natl Acad Sci USA. 2001; 98: 5856-61.

35. Mattson MP, Haberman F. Folate and homocysteine metabolism: therapeutic targets in cardiovascular and neurodegenerative disorders. Curr Med Chem. 2003; 10: 1923-9.

36. Helliwell B, Aylesworth R, McDowell I, Baumgarten M, Sykes E. Correlates of nonparticipation in the Canadian Study of Health and Aging. Int Psychogeriatr. 2001; 13 Supp 1: 49-56.

37. Frank RA, Galasko D, Hampel H, Hardy J, de Leon MJ, Mehta PD, et al. Biological markers for therapeutic trials in Alzheimer's disease. Proceedings of the biological markers working group; NIA initiative on neuroimaging in Alzheimer's disease. Neurobiol Aging. 2003; 24: 521-36. 
38. Hampel H, Mitchell A, Blennow K, Frank RA, Brettschneider S, Weller L, et al. Core biological marker candidates of Alzheimer's disease - perspectives for diagnosis, prediction of outcome and reflection of biological activity. J Neural Transm. 2004; 111: 247-72.

39. Klunk WE, Engler H, Nordberg A, Bacskai BJ, Wang Y, Price JC, et al. Imaging the pathology of Alzheimer's disease: amyloidimaging with positron emission tomography. Neuroimaging Clin N Am. 2003; 13: 781-9, ix.

40. Resnick SM, Henderson VW. Hormone therapy and risk of Alzheimer disease: a critical time. JAMA. 2002; 288: 2170-2.
41. Fratiglioni L, Paillard-Borg S, Winblad B. An active and socially integrated lifestyle in late life might protect against dementia. Lancet Neurol. 2004; 3: 343-53.

42. Sano M. Current concepts in the prevention of Alzheimer's disease. CNS Spectr. 2003; 8: 846-53.

43. Black SE, Patterson C, Feightner J. Preventing dementia. Can J Neurol Sci. 2001; 28 Suppl 1: S56-66.

44. Knopman D. Pharmacotherapy for Alzheimer's disease: 2002. Clin Neuropharmacol. 2003; 26: 93-101. 